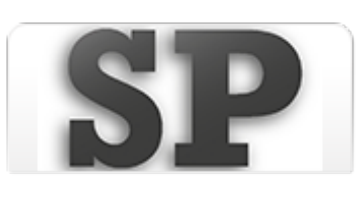

Sociedades precapitalistas

ISSN: 2250-5121

publicaciones@fahce.unlp.edu.ar

Universidad Nacional de La Plata

Argentina

\title{
Presentación del Dossier: Formas de explotación del trabajo y relaciones laborales en sociedades preindustriales
}

\author{
Colombo, Octavio \\ Presentación del Dossier: Formas de explotación del trabajo y relaciones laborales en sociedades \\ preindustriales \\ Sociedades precapitalistas, núm. 9, 2020 \\ Universidad Nacional de La Plata, Argentina \\ DOI: https://doi.org/10.24215/22505121e049
}

Atribución no comercial compartir igual (CC BY-NC-SA) 4.0 
Dossier: Formas de explotación del trabajo y relaciones laborales en sociedades preindustriales

\section{Presentación del Dossier: Formas de explotación del trabajo y relaciones laborales en sociedades preindustriales}

Hace apenas dos o tres décadas, las discusiones sobre el llamado "fin del trabajo" caracterizaban un panorama intelectual y político signado por el triunfo del neoliberalismo y el impacto de la globalización. Hoy, en cambio, la problemática de la precarización del trabajo, esto es, del deterioro de las condiciones materiales, económicas y sociales del trabajo asalariado, ocupa un lugar relevante en la agenda pública. Al mismo tiempo, no hay plan de reestructuración capitalista que no gire en torno al problema de la "flexibilización", como se dice eufemísticamente, de las condiciones laborales. El capital globalizado no hace más que cumplir ese designio propio de su naturaleza, que consiste (al decir de Marx y Engels en el Manifiesto Comunista) en revolucionar constantemente las fuerzas productivas y, con ello, el conjunto de las relaciones sociales.

En este contexto, la así llamada "historia del trabajo" se presenta como la rama más dinámica y renovadora de la historia social en la actualidad. Ciertamente, estamos ante un tema clásico y fundante de las ciencias sociales: la centralidad de las formas de organización del trabajo para la vida social difícilmente pueda considerarse una novedad, aunque las modas historiográficas de las últimas décadas la hayan relegado coyunturalmente a un papel marginal en el campo académico. Sin embargo, como siempre ocurre cuando se vuelven a indagar viejos problemas con nuevas preguntas, asistimos en la actualidad a un intento por aprehender el carácter heterogéneo y complejo de los sistemas de trabajo pretéritos, como así también la versatilidad de las clases dominantes en sus estrategias de dominación. Encuadrados en esa problemática, los trabajos que conforman este Dossier abarcan, además, casos muy diversos, correspondientes a la historia antigua, medieval y moderna, apuntando a consolidar una perspectiva de larga duración en un campo todavía demasiado desbalanceado, por la mayor disponibilidad de documentación, hacia la historia contemporánea. El análisis comparativo y los problemas conceptuales generales que emergen de este recorrido aspiran a ser de utilidad también para otros estudios de caso que se contengan en la misma problemática. Así, a partir de análisis concretos informados por una perspectiva general, se podrá construir colectivamente la historia del trabajo, es decir, la historia de las formas de dominación y control de los productores, que demandan las inquietudes de nuestro tiempo.

\section{BY-NC-SA}

